\title{
AN INTEGRATED COMPUTATIONAL TOOL FOR CONSEQUENCE ANALYSIS IN THE PROCESS INDUSTRY
}

\author{
I. B. TOLENTINO ${ }^{1}$, T. D. FERREIRA ${ }^{1}$ and S. S. V. VIANNA ${ }^{1}$ \\ ${ }^{1}$ University of Campinas, Faculty of Chemical Engineering \\ E-mail: itolentino@feq.unicamp.br
}

\begin{abstract}
This paper presents a new computational tool developed for consequence analysis modelling as far as gas releases are concerned. The code comprises the following models: discharge, dispersion, vapour cloud explosion and jet fire. The code also includes advance RSM (Response Surface Methodology) curves based on CFD (Computational Fluid Dynamics) findings. Four cases are compared with literature data in order to validate the tool. Good agreement with benchmarking cases is observed.
\end{abstract}

\section{INTRODUCTION}

Accidents in the chemical industry are always a social problem. They are object of study worldwide. The major contributor to accidents and losses in the process plant is the vapour cloud explosion (VCE), followed by fires (Crowl and Louvar, 2001). Although the analysis of the aftermath of accidents can help on understanding the causes of accidents, it is important to bear in mind that it is not possible to calculate future consequences based on the previous knowledge only. There are however various aspects that must be considered when modelling accidental scenarios.

In this context, computational programs play an important role on the calculation of physical effects of possible accidents. However, most software of consequence analysis are costly and they do require too many details of the process plant (which sometimes are unknown) in order to model the effects. Hence, the objective of this paper is to present a simple-to-use consequence analysis tool, namely CASE (Consequence Analysis Simulation Environment) that performs the calculation of all phases of an accident based on well established consequence models, as far as gas releases are concerned. CASE is also able to deal with very advanced response surface based on CFD data.

\section{METHODOLOGY}

The tool has been coded in Fortran. The framework of the computational tool is carefully detailed in Figure 1 below: 


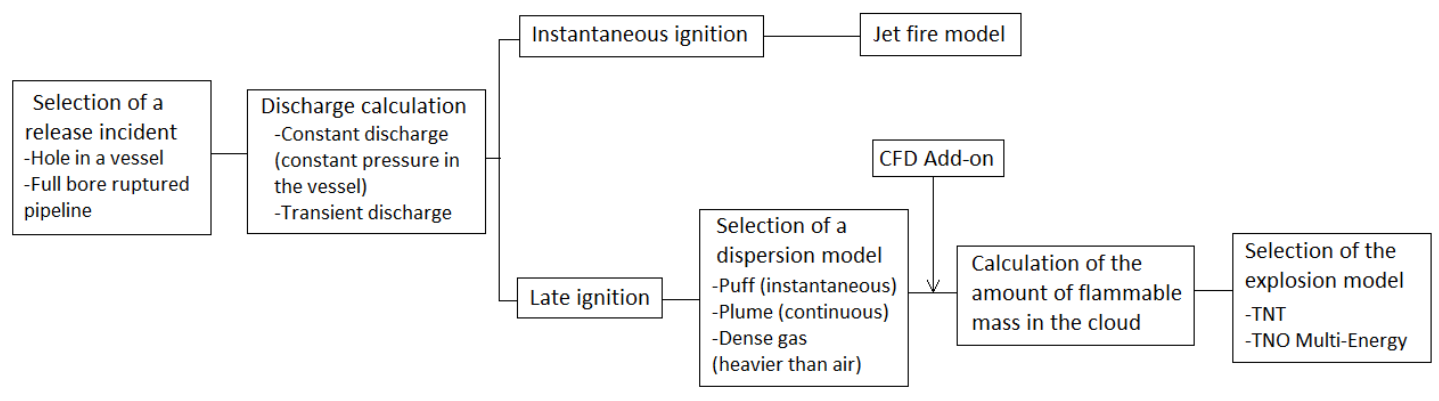

Figure 1 - Framework of CASE computational tool.

\subsection{Discharge Models}

Currently two releases model are considered: transient and initial discharge rate. The types of discharges addressed in the tool (Figure 1) comprise the most common scenarios. It is important to highlight that DnV - Phast software, which is wide known, also follows the same approach (Witlox et al., 2014). For the case in which a hole in a tank is considered, the discharge rate is calculated according to Equations 1 and 2 (Van den Bosch and Weterings, 2005), depending on the type of flow (sonic or subsonic, respectively). The sonic flow occurs when the flow of gas becomes independent of the downstream pressure. The discharge rate for full bore rupture of a pipeline (Equation 3) was also addressed according to Van den Bosch and Weterings (2005), where the discharge rate is a function of time.

$$
\begin{aligned}
& q_{i, \text { sonic }}=C_{d} \cdot A_{h} \cdot P_{i} \cdot \sqrt{\frac{\gamma \cdot M W}{R_{g} \cdot T_{\text {initial }}} \cdot\left(\frac{2}{\gamma+1}\right)^{(\gamma+1) /(\gamma-1)}} \\
& q_{i, \text { subsonic }}=C_{d} \cdot A_{h} \cdot P_{i} \cdot \sqrt{\frac{2 \cdot M W}{R_{g} \cdot T_{\text {initial }}} \cdot\left(\frac{\gamma}{\gamma-1}\right)\left[\left(\frac{P_{a}}{P_{i}}\right)^{2 / \gamma}-\left(\frac{P_{a}}{P_{i}}\right)^{\gamma+1 / \gamma}\right]} \\
& q(t)=\frac{q_{0}}{\left(1+\frac{Q_{0}}{t_{B} \cdot q_{0}}\right)} \cdot\left[\frac{Q_{0}}{t_{B} \cdot q_{0}} \cdot \exp \left(-\frac{t}{t_{B}}\right)+\exp \left(-t \cdot t_{B} \cdot\left(\frac{q_{0}}{Q_{0}}\right)^{2}\right]\right.
\end{aligned}
$$

\subsection{Dispersion Models}

The gas dispersion modelling is based on the classical Gaussian model taking into account the buoyancy of the gas. This model was chosen because it is well defined, well validated and available in software packages (AIChE - American Institute of Chemical Engineers, 2000).

On the other hand, when the gas has higher density than the air, it is considered a dense gas (positive buoyant) and the dispersion model used in this case is the one suggested by Britter and McQuaid model (AIChE, 2000). 
It is important to point out that the plume model is constructed to calculate the dispersion for a continuous constant leakage rate. As this work deals also with transient leakage, the plume Gaussian model is not appropriated in such scenarios. Instead, it should be used the puff model, considering the total mass released at all transient leakage time. This approach can only be made when the emission has a shorter time compared with the travel time of the cloud. AIChE (2000) considers that a leakage that takes less than 10 minutes can be considered as a puff. Also, just as in the DnV-Phast software, it was assumed that the release direction is the same as the wind direction (Witlox et al., 2014). The equations for puff (instantaneous) and plume (continuous) Gaussian models are presented respectively in the Equations 4 and 5 below:

$$
C=\frac{Q_{\text {total }}}{(2 \cdot \pi)^{\frac{3}{2}} \cdot \sigma_{x} \cdot \sigma_{y} \cdot \sigma_{z}} \cdot \exp \left[\frac{-1}{2} \cdot\left(\frac{y}{\sigma_{y}}\right)^{2}\right] \cdot \exp \left[\frac{-1}{2} \cdot\left(\frac{x-u \cdot t}{\sigma_{x}}\right)^{2}\right] \cdot\left\{\exp \left[\frac{-1}{2} \cdot\left(\frac{z-H}{\sigma_{z}}\right)^{2}\right]+\exp \left[\frac{-1}{2} \cdot\left(\frac{z+H}{\sigma_{z}}\right)^{2}\right]\right\}
$$

$$
C=\frac{q_{i}}{2 \cdot \pi \cdot \sigma_{y} \cdot \sigma_{z} \cdot u} \cdot \exp \left[\frac{-1}{2} \cdot\left(\frac{y}{\sigma_{y}}\right)^{2}\right] \cdot\left\{\exp \left[\frac{-1}{2} \cdot\left(\frac{z-H}{\sigma_{z}}\right)^{2}\right]+\exp \left[\frac{-1}{2} \cdot\left(\frac{z+H}{\sigma_{z}}\right)^{2}\right]\right\}
$$

\subsection{Flammable Mass}

The total mass within the flammable range was determined by Equations 6, 7 and 8, for both instantaneous (Equations 6 and 7) and continuous release, respectively (Lees, 2005).

$$
\begin{gathered}
Q_{\text {flam }}=Q_{\text {total }} \cdot\left\{\operatorname{erf}\left[\left(\ln \frac{C_{c c}}{L F L}\right)^{1 / 2}\right]-\operatorname{erf}\left[\left(\ln \frac{C_{c c}}{U F L}\right)^{1 / 2}\right]-\frac{2 \cdot L F L}{(\pi)^{1 / 2} \cdot C_{c c}} \cdot\left[\left(\ln \frac{C_{c c}}{L F L}\right)^{1 / 2}\right]+\right. \\
\left.\frac{2 . U F L}{(\pi)^{1 / 2} \cdot C_{c c}} \cdot\left[\left(\ln \frac{C_{c c}}{U F L}\right)^{1 / 2}\right]\right\} \quad \text { if } C_{c c}>U F L \\
Q_{\text {flam }}=Q_{\text {total }} \cdot\left\{\operatorname{erf}\left[\left(\ln \frac{C_{c c}}{L F L}\right)^{1 / 2}\right]-\frac{2 \cdot L F L}{(\pi)^{1 / 2} \cdot C_{c c}} \cdot\left[\left(\ln \frac{C_{c c}}{L F L}\right)^{1 / 2}\right]\right\} \text { if } C_{c c}<U F L \\
Q_{\text {flam }}=\left(\frac{1}{\pi \cdot D}\right)^{1 / f} \cdot \frac{f}{f+1} \cdot\left(\frac{q_{i}}{u}\right)^{(f+1) / f} \cdot\left(\frac{1}{L F L^{1 / f}}-\frac{1}{U F L^{1 / f}}\right)
\end{gathered}
$$

\section{$\underline{\text { CFD Add - on. A response surface approach }}$}

The great differential of the tool proposed in this research is the coupling between CFD and stochastic techniques for simulation of thousand of accidental scenarios with the same level of accuracy of CFD.

The idea behind the tool is based on the tuning of response surfaces ( $1^{\text {st }}$ and $2^{\text {nd }}$ order) using a set of CFD data as suggested by Ferreira and Vianna (2014). The dispersion of gas in an offshore plant was analyzed and the flammable gas cloud size (volume) of the mixture air-fuel was obtained considering two variables: $\mathrm{R}$ and $\varphi$, which represent respectively a non-dimensional leak rate and the angle between the leakage and wind directions. 
Once various combinations of wind and leak direction as well as wind speed and leak rate are considered, the flammable volume of the vapour cloud dispersed through the air is obtained.

\subsection{Vapour Cloud Explosion}

The following step is to determine the overpressure caused by an explosion when the cloud is ignited. The models used in this work were the TNT and the TNO Multi-Energy models. The MultiEnergy model uses charts to represent the relationship between parameters. In order to obtain those parameters in a computational tool, they were estimated according to the analytical curves of the work of Alonso et al. (2006).

\subsection{Jet Fire Model}

Jet fire is a physical effect when the combustion of a substance happens immediately when the compressed gas is being released. This means that the jet fire occurs when the substance is ignited right before it leaks, leaving no time for the dispersion of material in the atmosphere to take place. The model used in such cases (Equation 9) was developed by Mudan and Croce (1988), as described in AIChE (2000). It was only studied vertical flames as the vertical flame provides the largest radiant flux at any receptor point (AIChE, 2000).

$$
E_{r}=\tau_{a} \cdot \eta \cdot q_{i} \cdot \Delta H_{c} \cdot F_{p}
$$

\section{RESULTS}

Four cases already studied in the literature were simulated and their results were compared to those obtained from the literature.

\subsection{Case I}

The first scenario is the transient discharge through a hole of $100 \mathrm{~mm}$ in a vessel of $100 \mathrm{~m}^{3}$ (Van den Bosch and Weterings, 2005). The substance considered was hydrogen (molecular weight of $2.02 \mathrm{~g} / \mathrm{mol}$ ), with initial pressure of $50.0 \mathrm{bar}$ and $288.15 \mathrm{~K}$, and a heat capacity ratio of 1.40 . The discharge coefficient is 0.62 . The result of the discharge is presented in Figure 2(a). Analysis of the plot shows good agreement between CASE and the results obtained by Van den Bosch and Weterings, 2005.

The discharge model was also tested for the transient emission of methane (molecular weight $16.04 \mathrm{~g} / \mathrm{mol}$ and heat capacity ratio 1.31) as the result of a full bore rupture of a pipeline of $1.219 \mathrm{~m}$ diameter, 100,000.0 m length and 0.00003 roughness (Van den Bosch and Weterings, 2005). The initial pressure was 68.5 bar, the final is the atmospheric pressure and the discharge coefficient for full bore ruptured pipeline is usually 1.0 (Van den Bosch and Weterings, 2005). Figure 2(b) also shows good agreement between the simulated scenario and literature data. 


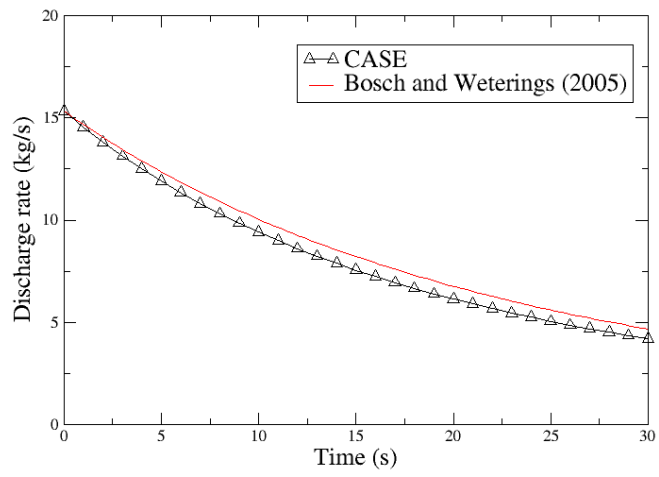

(a)

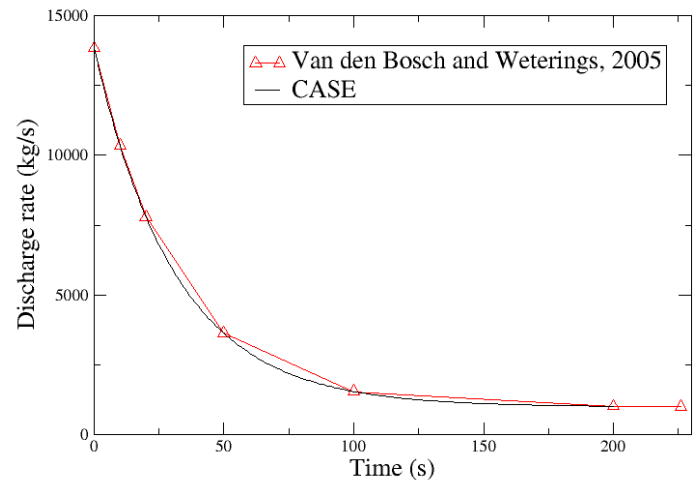

(b)

Figure 2 - Transient discharge through (a) hole in a vessel and (b) full bore ruptured pipeline.

\subsection{Case II}

The second scenario concerns the gas dispersion and explosion modelling. The initial leak rate has been considered, Figure 2(a). For dispersion calculation, it has been considered that the emission occurred on ground level and the class of stability of Pasquill-Guifford was F, with a $2 \mathrm{~m} / \mathrm{s}$ wind speed. The upper and lower flammability limit of hydrogen are 4.0 and 75.0 of percentage of fuel in air, respectively (Crowl and Louvar, 2001). For the TNT explosion model, it was considered an efficiency of 0.05 of the explosion, and for the TNO Multi-Energy model, the inputs are the heat of combustion of the substance $(120 \mathrm{MJ} / \mathrm{kg})$ and the stoichiometric heat of combustion in percentage of volume of 0.3. Figure 3(a) shows the gas cloud size considering the lower flammability.

The flammable gas cloud volume is used in the explosion model. The overpressure was calculated by the two models previously mentioned. The overpressure results are shown in Figure 3(b). Analysis of the plot shows a significant difference between models in the near field. This is due to coarse estimation of the equivalent mass of dynamite as it does depend on the efficiency of the explosion. On the other hand both models agree well in the far field. As the TNO approach considers the decay of released energy with increasing distance from the source, the good agreement for such cases was expected. 


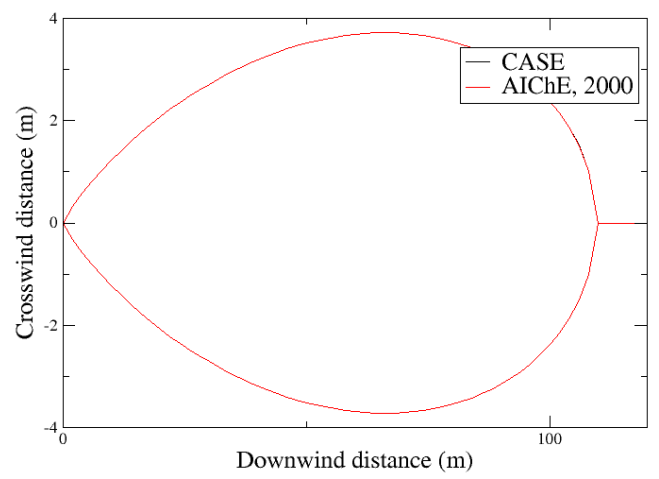

(a)

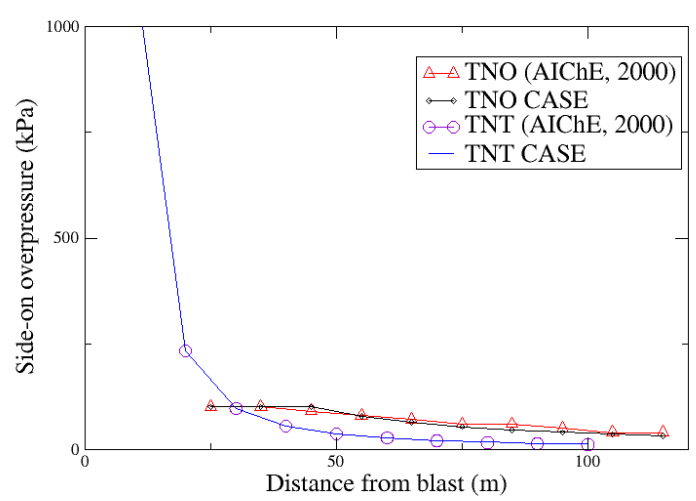

(b)

Figure 3 - (a) Dispersion and (b) overpressure results for case II.

\subsection{Case III}

The jet fire calculation considered methane (heat capacity of $1685.63 \mathrm{~J} / \mathrm{kg} . \mathrm{K}$ ) release from a hole of $0.1 \mathrm{~m}$ in a $100 \mathrm{~m}^{3}$ vessel. The initial pressure of $50 \mathrm{bar}$ and the adiabatic temperature of the flame of $2200.0 \mathrm{~K}$ were used. The incident radiation flux was measured 15 meters from the flame. It has been considered a relative humidity of $50 \%$, as well as a fraction of 0.2 of the total energy converted in radiation. Figure 4 shows that the radiation decreases with time. As the radiation is proportionally dependant on the discharge rate, such behaviour is expected.

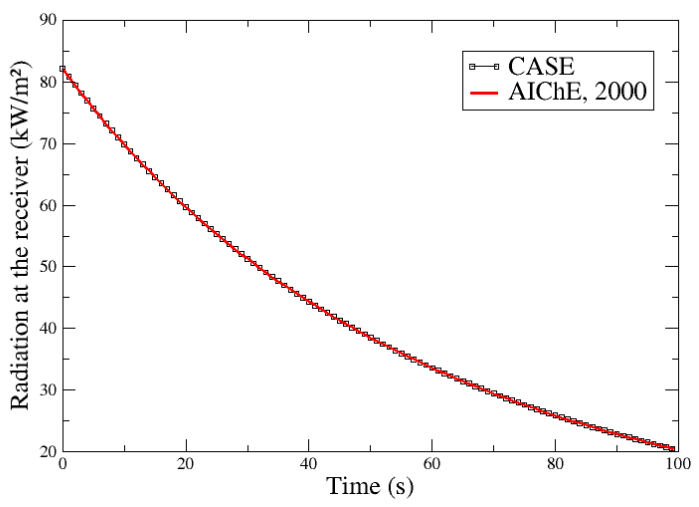

Figure 4 - Radiation of a jet fire caused by a transient emission of gas (case III).

\subsection{Case IV}

The volume of the flammable cloud can also be calculated according to the work of Ferreira and Vianna (2014). As this work predicts the flammable volume with response surfaces, the tool can also provide precise results based on CFD modelling. 
This is an important and pioneer characteristic of CASE, as the user is allowed to use CFD data to calculate a specific output of the accident in the tool and all other subsequent effects can be calculated as part of the consequence analysis. The equations obtained in the work were implemented in the computational tool, and some results are shown in Table 1 for natural gas, with density 1.44 $\mathrm{kg} / \mathrm{m}^{3}$. The equations are able to predict well the flammable cloud volume according to CFD results.

Table 1 - Results of the model of Ferreira and Vianna (2014) applied in the tool.

\begin{tabular}{llcccc}
\hline Quadrant & $\mathrm{R}$ & $\varphi$ & $\begin{array}{c}\text { Volume of the } \\
\text { flammable cloud }\left(\mathrm{m}^{3}\right)\end{array}$ & $\begin{array}{c}\text { Volume of the flammable } \\
\text { cloud }\left(\mathrm{m}^{3}\right)-\text { CFD results }\end{array}$ & Difference $(\%)$ \\
\hline 1 & 0.03 & $0^{\circ}$ & 1021.01 & 1095.24 & 6.78 \\
2 & 0.15 & 135 & 10432.19 & 9884.08 & -5.55 \\
3 & 0.30 & 270 & 9213.23 & 8765.37 & -5.11 \\
4 & 0.30 & 360 & 12847.53 & 14263.10 & 9.92 \\
\hline
\end{tabular}

Figure 5 below shows the response surfaces implemented in the code. The $\mathrm{x}$-axis shows the non-dimensional leak rate $(R)$ while the $y$-axis shows the relative wind/leak direction $(\varphi)$. The vertical axis presents the volume of the cloud.

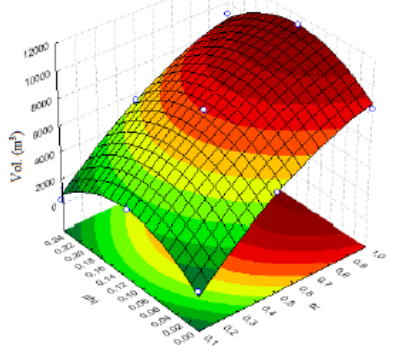

(a) Quadrant 01

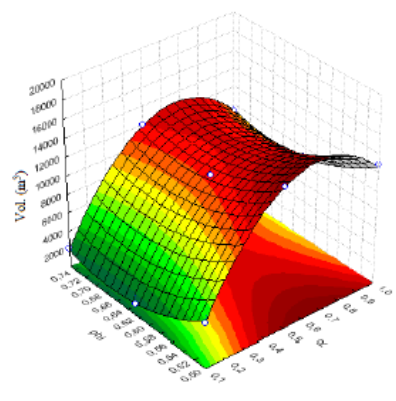

(c) Quadrant 03

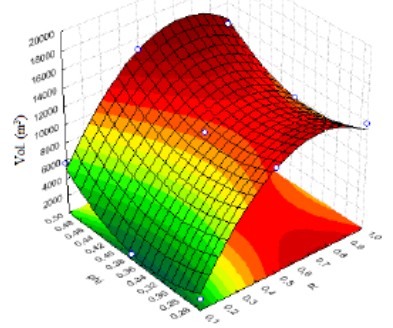

(b) Quadrant 02

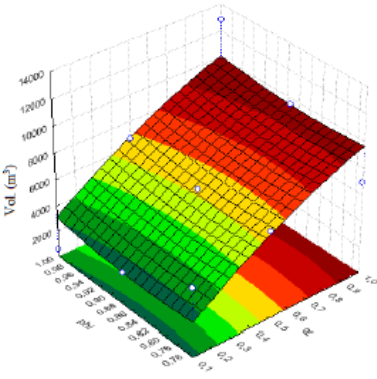

(d) Quadrant 04

Figure 5 - Response surfaces for each quadrant (due to Ferreira and Vianna, 2014)

\section{NOMENCLATURE}

$\mathrm{A}_{\mathrm{h}}:$ hole area $\left[\mathrm{m}^{2}\right]$

$\mathrm{C}$ : concentration of the cloud $\left[\mathrm{mg} / \mathrm{m}^{3}\right]$

Ccc: concentration of the centre of the cloud $\left[\mathrm{mg}_{\text {fuel }} / \mathrm{m}^{3}\right.$ cloud $]$

$\mathrm{C}_{\mathrm{d}}$ : discharge coefficient [unitless]

D: meteorological parameter for 


\section{9 a 22 de outubro de 2014 \\ Florianópolis/SC}

Marshall's equation

Er: radiant flux at the receiver $\left[\mathrm{kW} / \mathrm{m}^{2}\right]$

$\mathrm{f}$ : meteorological parameter for

Marshall's equation

Fp: point source view factor $\left[\mathrm{m}^{-2}\right]$

$\mathrm{H}$ : height of the leakage [m]

LFL: lower flammability

limit concentration $\left[\mathrm{kg}_{\text {fuel }} / \mathrm{m}^{3}\right.$ air $]$

MW: molecular weight of the gas $[\mathrm{kg} / \mathrm{mol}]$

$\mathrm{P}_{\mathrm{i}}$ : pressure in the vessel $[\mathrm{Pa}]$

$\mathrm{P}_{\mathrm{a}}$ : atmospheric pressure (101325) $[\mathrm{Pa}]$

$\mathrm{q}_{0}$ : initial discharge rate $[\mathrm{kg} / \mathrm{s}]$

$\mathrm{Q}_{0}$ : initial total mass [kg]

$\mathrm{Q}_{\text {flam: }}$ total mass within

the flammability limits [kg]

$\mathrm{Q}_{\text {total }}$ : total mass released

from instantaneous release $[\mathrm{kg}]$

$\mathrm{Rg}$ : ideal gas constant [Pa.m $3 / \mathrm{mol} . \mathrm{K}]$ t: time [s]

$\mathrm{T}$ : temperature $[\mathrm{K}]$

$\mathrm{t}_{\mathrm{B}}$ : time constant $[\mathrm{s}]$

$\mathrm{u}$ : wind speed $[\mathrm{m} / \mathrm{s}]$

UFL: upper flammability

limit concentration $\left[\mathrm{kg}_{\text {fuel }} / \mathrm{m}^{3}\right.$ air $]$

$\mathrm{x}$ : downwind direction $[\mathrm{m}]$

$\mathrm{y}$ : crosswind direction $[\mathrm{m}]$

$\mathrm{z}$ : vertical direction $[\mathrm{m}]$

$\gamma$ : heat capacity ratio $(\mathrm{Cp} / \mathrm{Cv})$ [unitless]

$\Delta \mathrm{Hc}$ : energy of combustion of

the fuel $[\mathrm{kJ} / \mathrm{kg}]$

$\eta$ : efficiency of explosion [unitless]

$\sigma_{x}, \sigma_{x}, \sigma_{x}$ : dispersion coefficients of

Pasquill-Guifford stability class [unitless]

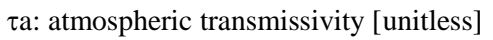

\section{CONCLUSIONS}

CASE was able to address gas releases' consequences with good agreement with the literature. The greatest difference was obtained in VCE result, but it was verified that the difference lies on the specific characteristic of both TNT and TNO Multi-Energy models.

The most innovative characteristic of the tool is the possibility of integrating equations of response surfaces based on CFD simulations in it. The user can choose whether he prefers to obtain the flammable volume by using equations from the literature or by using response surfaces. The user can also obtain response surfaces based on CFD data and implement them in the tool for a desirable scenario. Finally, CASE is fairly simple to use and takes little computational effort.

\section{REFERENCES}

AIChE (AMERICAN INSTITUTE OF CHEMICAL ENGINEERS) - CCPS (Center for Chemical Process Safety) Guidelines for Chemical Process Quantitative Risk Analysis, second edition, New York, USA, 2000, p. 57-243.

ALONSO, F. D.; FERRADÁS, E. G.; PÉREZ, J. F. S.; AZNAR, A. M.; GIMENO, J. R.; ALONSO, J. M. Characteristic overpressure-impulse-distance curves for vapour cloud explosions using the TNO Multi-Energy model. J. of Hazard. Mater., 2006, p. 734-741.

CROWL, D. A.; LOUVAR, J. F. Chemical Process Safety: Fundamentals with Applications. Second edition. Prentice Hall, 2001.

FERREIRA, T. D; VIANNA, S. S V. A novel coupled response surface for flammable gas cloud volume prediction. Int. J. of Model. and Simul. for the Pet. Ind, submitted, 2014.

LEES, F. P. Loss Prevention in the Process Industries. Hazard Identification Assessment and Control. Third edition, Butterworth-Heinemann, Oxford, UK, 2005, p 1006-1008.

VAN DEN BOSCH, C. J. H.; WETERINGS, R. A. P. M. (Editors). Methods for the calculation of physical effects - due to releases of hazardous materials (liquids and gases) -. 'Yellow Book', 2005, p. 2.63 - 2.69, 2.73 - 2.74, 2.127 - 2.130, $2.131-2.132$ and 5.48 .

WITLOX, H. W. M.; HARPER, M.; OKE, A.; STENE, J. Validation of discharge and atmospheric dispersion for unpressurized carbon dioxide releases. Process Safety and Environment Protection, 2014, p 3-16. 